\title{
Implementasi Algoritma Mondrian Multidimensional K- Anonymity pada Biodata Calon Legislatif
}

\author{
Adam Akbar ${ }^{1}$, Rivanda Putra Pratama ${ }^{2}$, Nur Aini Rakhmawati ${ }^{3}$ \\ Departemen Sistem Informasi \\ Institut Teknologi Sepuluh Nopember \\ Surabaya, Indonesia \\ e-mail: 19adamakbar.id@gmail.com, ${ }^{2}$ rivanda.19052@mhs.its.ac.id, ${ }^{3}$ nur.aini@is.its.ac.id \\ Diajukan: 16 Januari 2021; Direvisi: 19 Maret 2021; Diterima: 26 Maret 2021
}

\begin{abstract}
Abstrak
Uni Eropa menerbitkan sebuah peraturan yang bernama General Data Protection Regulation (GDPR) untuk menjaga privasi warga. Peraturan ini meregulasi penyebaran data-data pribadi seperti nama, nomor telepon atau alamat yang mungkin akan digunakan untuk tujuan tertentu. Salah satu teknik yang dapat digunakan untuk menyebarkan data tanpa melanggar privasi dari subjek pemilik data adalah K-Anonymity. K-Anonymity memodifikasi nilai quasi-identifier hingga subjek tidak dapat dikenali lagi tetapi dataset tetap mengandung informasi yang diperlukan. Artikel ini telah mengimplementasikan $K$ Anonymity pada data Calon Legislatif untuk Pemilihan Umum Calon Legislatif tahun 2019 yang dihimpun dari laman resmi Komisi Pemilihan Umum. Dengan algoritma Mondrian Multidimensional K-Anonymity hasil anonimisasi menunjukkan bahwa masih terdapat data yang unik. Namun, dari hasil visualisasi terlihat hampir semua data memiliki anonimitas sama, yang dimungkinkan karena jumlah data partisi yang kurang banyak ataupun kurangnya keberagaman data.
\end{abstract}

Kata kunci: Anonimisasi, Privasi data, K-Anonymity, Mondrian, Calon legislatif.

\begin{abstract}
The European Union issued a regulation called the General Data Protection Regulation (GDPR) to protect the privacy of its citizens. The GDPR regulates the distribution of personal data such as name, telephone number or address which may be used for certain purposes. One of the techniques that can be used to disseminate data without violating the privacy of general data is K-Anonymity. K-Anonymity modifies the quasi-identifier value until the subject can no longer be recognized but the dataset still contains the necessary information. This article has implemented K-Anonymity in data on Indonesian Legislative Candidates for The 2019 General Election compiled from the official website of the General Election Commission. The anonymization results show that there are still unique data by using the Mondrian Multidimensional K-Anonymity algorithm. However, from the visualization results, it can be seen that almost all data has the same anonymity, which is possible due to the insufficient number of partition data or the lack of data diversity.
\end{abstract}

Keywords: Anonymization, Data privacy, K-Anonymity, Mondrian, Legislative candidate.

\section{Pendahuluan}

General Data Protection Regulation (GDPR) merupakan peraturan yang berlaku di Uni Eropa sejak 25 Mei 2018 [1], [2]. GDPR diterbitkan untuk menggantikan peraturan sebelumnya yang bernama Data Protection Acts 1988-2003. GDPR memuat beberapa ketentuan yang sebelumnya tidak terdapat pada Data Protection Acts 1988-2003. GDPR merupakan jawaban atas kebutuhan Uni Eropa untuk proteksi modern di era internet saat ini. Secara sederhana, GDPR mengatur tentang privasi dan keamanan atas data masyarakat Uni Eropa yang dikumpulkan oleh siapa pun. Walau dengan batasan, GDPR mengizinkan pemberdayaan data subjek untuk tujuan tertentu misalnya penelitian. Beberapa metode seperti Pseudonymization atau Anonymization dapat menghasilkan kumpulan data (dataset) yang memuat banyak informasi dengan privasi yang tetap terjaga sesuai dengan ketentuan GDPR.

Salah satu model untuk Anonymization yang cukup populer adalah K-Anonymity yang diperkenalkan oleh Latanya Sweeney melalui artikelnya pada tahun 2002 [3]. Pada artikel tersebut, Sweeney menggunakan istilah quasi-identifier yang diperkenalkan oleh Dalenius [4] yaitu kumpulan 
atribut yang dapat menjadi pengenal identitas seperti nama, alamat, NIK, atau nomor telepon. Selain itu, beberapa atribut yang jika dikombinasikan dapat menjadi pengenal identitas, maka atribut-atribut tersebut termasuk quasi-identifier, sebagai contoh kombinasi tanggal lahir, jenis kelamin, dan kode pos dapat mengidentifikasi satu orang yang spesifik.

Secara sederhana, K-Anonymity dapat dicapai dengan melakukan generalization dan suppression pada quasi-identifier hingga nilai-nilai quasi-identifier pada setiap baris tidak unik dan minimal muncul sebanyak $k$. Sebagai penggambaran, Tabel 1 adalah dataset awal sebelum dilakukan $K$-Anonymity dan Tabel 2 merupakan dataset hasil K-Anonymity dari Tabel 1. Seperti yang dapat dilihat pada Tabel 2, supression dilakukan pada atribut nama dan generalization dilakukan pada atribut usia dan kota. Kolom nama diubah menjadi “*” untuk setiap nilainya. Sedangkan, kolom usia diubah menjadi bentuk rentang nilai, serta kolom kota yang menunjukkan wilayah digeneralisasi menjadi kolom provinsi. Dari Tabel 2 juga diketahui bahwa kolom \{nama, usia, provinsi \} yang bernilai $\{*, 21 \mathrm{~s} / \mathrm{d} 30$, Jawa Timur $\}$ telah muncul sebanyak 2 kali dan nilai $\{*, 31$ s/d 40, Jawa Timur $\}$ muncul sebanyak 3 kali, yang artinya nilai $k$ dari Tabel 2 adalah 2, karena diambil dari nilai kemunculan terkecil.

Tabel 1. Contoh dataset pasien rumah sakit.

\begin{tabular}{cccc}
\hline Nama & Usia & Usia & Penyakit \\
\hline Wyatt Montes & 23 & Surabaya & Asma \\
\hline Kimberley Archer & 40 & Sidoarjo & Kanker \\
\hline Hermione Goodwin & 40 & Sidoarjo & Osteoporosis \\
\hline Alessandro Raymond & 27 & Surabaya & Asma \\
\hline Ameera Wheeler & 34 & Malang & Kanker \\
\hline
\end{tabular}

Tabel 2. Generalization dan suppression pada contoh dataset pasien rumah sakit.

\begin{tabular}{cccc}
\hline Nama & Usia & Usia & Penyakit \\
\hline$*$ & $21 \mathrm{~s} / \mathrm{d} 30$ & Jawa Timur & Asma \\
\hline$*$ & $31 \mathrm{~s} / \mathrm{d} 40$ & Jawa Timur & Kanker \\
\hline$*$ & $31 \mathrm{~s} / \mathrm{d} 40$ & Jawa Timur & Osteoporosis \\
\hline$*$ & $21 \mathrm{~s} / \mathrm{d} \mathrm{30}$ & Jawa Timur & Asma \\
\hline$*$ & $31 \mathrm{~s} / \mathrm{d} \mathrm{40}$ & Jawa Timur & Kanker \\
\hline
\end{tabular}

Beberapa penelitian terhadap $K$-Anonymity telah dilakukan sebelumnya seperti pada artikel [5] yang telah mengimplementasikan dua algoritma $K$-Anonymity yaitu paritioning-based dan $k$-meansclustering-based pada data atlet pemain bola yang sering digunakan para peneliti untuk analisa peringkat atlet pemain bola. Selain data atlet pemain bola, artikel [6] menggunakan data medis pasien untuk menerapkan K-Anonymity yang berbasis bilinier pairings yang dapat melakukan pencarian data yang terenkripsi untuk menjamin privasi dari pasien. Tidak hanya data terstruktur yang perlu dilakukan anonimisasi, seperti pada artikel [7] yang menerapkan K-Anonymity berbasis MapReduce untuk melakukan anonimisasi pada big data dan berhasil mengurangi durasi pemrosesan pada big data. Sedangkan artikel [8] telah mengembangkan $K$-Anonymity berbasis analytic hierarchy process yang berhasil menekan tingkat informasi yang hilang (information loss) pada hasil anonimisasi.

Penelitian pada artikel ini akan melakukan implementasi $K$-Anonymity pada dataset biodata Calon Legislatif (Caleg) untuk Pemilihan Umum Anggota Legislatif (Pileg) di Indonesia pada tahun 2019.

\section{Metode Penelitian}

\subsection{Dataset}

Penelitian ini menggunakan dataset Caleg milik Nur Aini Rakhmawati [9] yang dihimpun menggunakan metode crawling pada laman resmi Komisi Pemilihan Umum untuk penelitian terdahulu. Dataset tersebut memiliki sekitar 36.000 baris data, namun dari semua baris tersebut, sekitar 26.000 baris ditemukan tidak lengkap karena tidak dilengkapi oleh Caleg yang bersangkutan. Dataset ini memiliki 15 kolom antara lain dapil, partai, nama, jk, lokasi, tahun_lahir, agama, nikah, pasangan, pendidikan, pekerjaan, status, motivasi, dan target.

\subsection{Pra-proses Dataset}

Beberapa atribut pada dataset dikodekan dalam bentuk desimal untuk memudahkan pemetaan program dan visualisasi. Daftar atribut dan detail pengodean dapat dilihat pada Tabel 3. 
Tabel 3. Daftar pengodean.

\begin{tabular}{|c|c|c|}
\hline Atribut & Nilai & Kode Nilai \\
\hline \multirow[t]{2}{*}{ jenis_kelamin } & Laki-Laki & 0 \\
\hline & Perempuan & 1 \\
\hline \multirow[t]{6}{*}{ agama } & Islam & 1 \\
\hline & Kristen Protestan & 2 \\
\hline & Katolik & 3 \\
\hline & Hindu & 4 \\
\hline & Budha & 5 \\
\hline & Konghucu & 6 \\
\hline \multirow[t]{3}{*}{ status_nikah } & Belum Menikah & 1 \\
\hline & Sudah Menikah & 2 \\
\hline & Pernah Menikah & 3 \\
\hline \multirow[t]{10}{*}{ pendidikan } & Tidak Sekolah & 1 \\
\hline & SD & 2 \\
\hline & SMP/Sederajat & 3 \\
\hline & SMA/Sederajat & 4 \\
\hline & D1 & 5 \\
\hline & D2 & 6 \\
\hline & D3 & 7 \\
\hline & D4/S1 & 8 \\
\hline & $\mathrm{S} 2$ & 9 \\
\hline & S3 & 10 \\
\hline \multirow[t]{6}{*}{ pekerjaan } & Tidak Bekerja & 1 \\
\hline & PNS & 2 \\
\hline & Wiraswasta & 3 \\
\hline & Pengusaha & 4 \\
\hline & Pegawai Pemerintah & 5 \\
\hline & Pensiunan & 6 \\
\hline
\end{tabular}

\subsection{Mondrian Multidimensional K-Anonymity}

Penelitian ini menggunakan algoritma Mondrian Multidimensional K-Anonymity [10] yang merupakan salah satu variasi dari $K$-Anonymity yang dikembangkan oleh LeFevre dkk. untuk memperoleh hasil anonimisasi yang lebih baik. Pada Mondrian Multidimensional K-Anonymity, sebelum melakukan anonimisasi, dataset dipartisi secara multi-dimensi menjadi bagian-bagian kecil berdasarkan nilai dari satu atribut quasi-identifier (sensitive column). Bagian-bagian kecil tersebut dipetakan pada dua atribut quasiidentifier yang lain (feature column) sebagai batas untuk rentang partisi. Ilustrasi hasil partisi dapat dilihat pada Gambar 1, di mana bagian (a) merupakan ilustrasi hasil partisi dengan dimensi tunggal, dan bagian (b) adalah ilustrasi untuk hasil partisi secara multi-dimensi yang telah dipaparkan.

Hasil partisi yang berupa bagian-bagian kecil dari dataset tersebut yang kemudian dilakukan anonimisasi. Pada penelitian ini, dua atribut yang digunakan untuk proses partisi adalah atribut tahun_lahir dan pekerjaan sebagai feature column, atribut partai sebagai sensitive column, dan nilai $k$ adalah 3 .

\subsection{Visualisasi}

Setelah dilakukan anonimisasi dengan algoritma Mondrian Multidimensional K-Anonymity, hasil dari proses partisi disajikan dalam bentuk grafik scatter plot dengan sumbu $x$ adalah atribut tahun_lahir dan sumbu $y$ adalah atribut pekerjaan, hal ini dimaksudkan untuk melihat persebaran partisi yang dipetakan pada masing-masing rentang nilai dari feature column. Kemudian, hasil partisi yang telah dilakukan anonimisasi disajikan dalam bentuk tabel yang berisi nilai dari atribut tahun lahir, pekerjaan, partai dan jumlah data (count) pada partisi. 

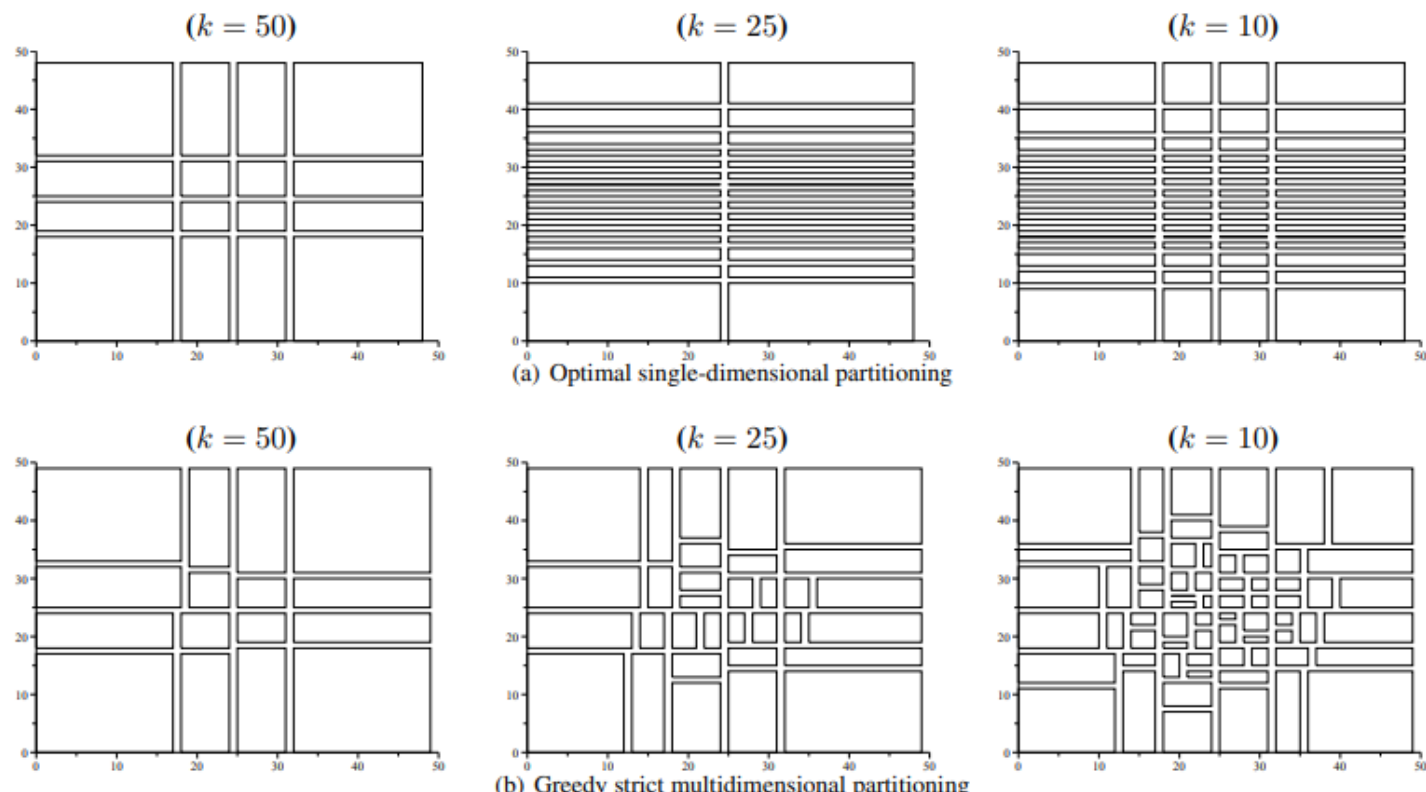

Gambar 1. Ilustrasi Hasil Partisi [10]

\section{Hasil dan Pembahasan}

\subsection{Inisialisasi Dataframe}

Penelitian ini menggunakan bahasa pemrograman Python. Untuk menggunakan algoritma Mondrian Multidimensional K-Anonymity yang selanjutnya disebut algoritma Mondrian, perlu untuk mengubah format dataset dari file CSV menjadi bentuk dataframe. Dataframe yang digunakan dalam penelitian ini menggunakan dataframe dari library Pandas. Serta, dataset yang digunakan dalam penelitian ini berjumlah 1000 data dan masing-masing data telah distandardisasi dan dibersihkan. Sampel dataset biodata Caleg yang digunakan pada penelitian ini dapat dilihat pada Tabel 4. Dataset secara lengkap dapat dilihat pada file data_penelitian.csv [11]. Dalam proses inisialisasi dataframe juga membagi kolom yang berjenis categorical. Kolom categorical tersebut adalah semua kolom dalam dataset yang bukan bertipe numerik. Kolom categorical pada dataset yang digunakan pada penelitian ini antara lain dapil, partai, dan lokasi_asal.

Tabel 4. Sampel dataset biodata caleg.

\begin{tabular}{|c|c|c|c|c|c|c|c|c|}
\hline Dapil & Partai & $\begin{array}{c}\text { Jenis } \\
\text { Kelamin } \\
\end{array}$ & $\begin{array}{c}\text { Lokasi } \\
\text { Asal } \\
\end{array}$ & $\begin{array}{l}\text { Tahun } \\
\text { Lahir }\end{array}$ & Agama & $\begin{array}{l}\text { Status } \\
\text { Nikah } \\
\end{array}$ & Pendidikan & Pekerjaan \\
\hline $\begin{array}{l}\text { aceh- } \\
\text { besar }\end{array}$ & $\begin{array}{c}\text { PARTAI } \\
\text { GERAKAN } \\
\text { INDONESIA } \\
\text { RAYA }\end{array}$ & Laki-Laki & $\begin{array}{l}\text { JAKARTA } \\
\text { BARAT }\end{array}$ & 1956 & Islam & $\begin{array}{c}\text { Sudah } \\
\text { Menikah }\end{array}$ & $\mathrm{S} 3$ & Wiraswasta \\
\hline $\begin{array}{l}\text { aceh- } \\
\text { besar }\end{array}$ & $\begin{array}{c}\text { PARTAI } \\
\text { KEADILAN } \\
\text { SEJAHTERA } \\
\end{array}$ & Laki-Laki & $\begin{array}{c}\text { ACEH } \\
\text { BESAR }\end{array}$ & 1967 & Islam & $\begin{array}{c}\text { Sudah } \\
\text { Menikah }\end{array}$ & SMA/Sederajat & $\begin{array}{c}\text { Pegawai } \\
\text { Pemerintah }\end{array}$ \\
\hline $\begin{array}{l}\text { bandung- } \\
\text { barat }\end{array}$ & $\begin{array}{c}\text { PARTAI } \\
\text { DEMOKRASI } \\
\text { INDONESIA } \\
\text { PERJUANGAN }\end{array}$ & Perempuan & $\begin{array}{c}\text { KOTA } \\
\text { BEKASI }\end{array}$ & 1967 & $\begin{array}{l}\text { Kristen } \\
\text { Protestan }\end{array}$ & $\begin{array}{l}\text { Belum } \\
\text { Menikah }\end{array}$ & SMA/Sederajat & Wiraswasta \\
\hline $\begin{array}{l}\text { aceh- } \\
\text { besar }\end{array}$ & $\begin{array}{l}\text { PERSATUAN } \\
\text { INDONESIA }\end{array}$ & Perempuan & $\begin{array}{c}\text { ACEH } \\
\text { BESAR }\end{array}$ & 1986 & Islam & $\begin{array}{c}\text { Sudah } \\
\text { Menikah }\end{array}$ & D4/S1 & $\begin{array}{c}\text { Tidak } \\
\text { Bekerja }\end{array}$ \\
\hline $\begin{array}{l}\text { bandung- } \\
\text { barat }\end{array}$ & $\begin{array}{c}\text { PARTAI } \\
\text { GOLONGAN } \\
\text { KARYA } \\
\end{array}$ & Perempuan & $\begin{array}{c}\text { KOTA } \\
\text { BANDUNG }\end{array}$ & 1972 & Islam & $\begin{array}{l}\text { Belum } \\
\text { Menikah }\end{array}$ & SMA/Sederajat & Pengusaha \\
\hline
\end{tabular}

\subsection{Mengubah ke Bentuk Kategori Angka}

Mengubah kolom yang memiliki kategori bukan angka ke bentuk kategori angka diperlukan untuk memudahkan komputasi pembelajaran mesin. Kolom yang perlu diubah ke bentuk kategori angka pada 
penelitian ini antara lain jenis_kelamin, agama, status_nikah, pendidikan, dan pekerjaan. Contoh hasil perubahan kategori angka dapat dilihat pada Tabel 5.

Tabel 5. Contoh hasil perubahan kategori angka.

\begin{tabular}{ccccccccc}
\hline Dapil & Partai & $\begin{array}{c}\text { Jenis } \\
\text { Kelamin }\end{array}$ & $\begin{array}{c}\text { Lokasi } \\
\text { Asal }\end{array}$ & $\begin{array}{c}\text { Tahun } \\
\text { Lahir }\end{array}$ & Agama & $\begin{array}{c}\text { Status } \\
\text { Nikah }\end{array}$ & Pendidikan & Pekerjaan \\
\hline $\begin{array}{c}\text { aceh- } \\
\text { besar }\end{array}$ & $\begin{array}{c}\text { PARTAI } \\
\text { GERAKAN } \\
\begin{array}{c}\text { INDONESIA } \\
\text { RAYA }\end{array}\end{array}$ & 0 & $\begin{array}{c}\text { JAKARTA } \\
\text { BARAT }\end{array}$ & 1956 & 1 & 2 & 10 & 3 \\
\hline $\begin{array}{c}\text { aceh- } \\
\text { besar }\end{array}$ & $\begin{array}{c}\text { PARTAI } \\
\text { KEADILAN } \\
\text { SEJAHTERA }\end{array}$ & 0 & $\begin{array}{c}\text { ACEH } \\
\text { BESAR }\end{array}$ & 1967 & 1 & 2 & 4 & 5 \\
\hline $\begin{array}{c}\text { PARTAI } \\
\text { bandung- } \\
\text { barat }\end{array}$ & $\begin{array}{c}\text { DEMOKRASI } \\
\text { INDONESIA } \\
\text { PERJUANGAN }\end{array}$ & 1 & $\begin{array}{c}\text { KOTA } \\
\text { BEKASI }\end{array}$ & 1967 & 2 & 1 & 4 & 3 \\
\hline $\begin{array}{c}\text { aceh- } \\
\text { besar }\end{array}$ & $\begin{array}{c}\text { PERSATUAN } \\
\text { INDONESIA }\end{array}$ & 1 & $\begin{array}{c}\text { ACEH } \\
\text { BESAR }\end{array}$ & 1986 & 1 & 2 & 8 & 1 \\
\hline $\begin{array}{c}\text { Pandung- } \\
\text { barat }\end{array}$ & $\begin{array}{c}\text { GOLONGAN } \\
\text { KARYA }\end{array}$ & 1 & $\begin{array}{c}\text { KOTA } \\
\text { BANDUNG }\end{array}$ & 1972 & 1 & 1 & 4 & 4 \\
\hline
\end{tabular}

\subsection{Mendapatkan Nilai Rentang}

Proses awal dalam algoritma Mondrian adalah mendapatkan nilai rentang. Fungsi yang diterapkan akan mengembalikan nilai rentang dari semua kolom untuk partisi dataframe. Nilai rentang untuk kolom numerik diambil dari nilai maksimum dikurangi dengan nilai minimum yang terdapat pada kolom. Serta, nilai rentang untuk kolom kategorikal menggunakan nilai unik. Perhitungan nilai rentang dapat dicontohkan dengan kolom Tahun Lahir yang memiliki nilai maksimum $=1997$ dan nilai minimum $=1879$, sehingga nilai rentang dari kolom Tahun Lahir $=1997-1879=118$. Nilai rentang masing-masing kolom yang diperoleh dapat dilihat pada Tabel 6.

Tabel 6. Nilai rentang masing-masing kolom.

\begin{tabular}{cc}
\hline Kolom & Nilai Rentang \\
\hline Dapil & 7 \\
\hline Partai & 19 \\
\hline Jenis Kelamin & 1 \\
\hline Lokasi Asal & 61 \\
\hline Tahun Lahir & 118 \\
\hline Agama & 4 \\
\hline Status Nikah & 2 \\
\hline Pendidikan & 7 \\
\hline Pekerjaan & 5 \\
\hline
\end{tabular}

\subsection{Partisi Dataset}

Pada tahapan ini dataset dipartisi menjadi 2 bagian, yaitu left partition dan right partition. Dalam proses partisi terdapat beberapa masukan, antara lain dataframe, feature columns, sensitive column, full spans yang didapat dari proses sebelumnya, dan $i s \_k \_a n o n y m o u s ~ y a n g ~ m e n a n d a k a n$ apakah partisi dari dataframe telah memenuhi K-Anonymity atau tidak. Feature columns merupakan kumpulan kolom pada dataframe yang akan dipartisi berdasarkan anonimitasnya. Sedangkan, sensitive column merupakan kolom yang dapat menjadi kunci pengenal suatu data, sehingga kolom ini digunakan sebagai acuan dalam partisi. Nilai $k$ pada penelitian ini sebesar 3 yang merupakan nilai bawaan dari fungsi algoritma Mondrian. Feature columns yang digunakan pada penelitian ini adalah tahun lahir dan pekerjaan, serta sensitive column adalah partai. Jumlah partisi yang diperoleh dari proses ini sebanyak 70 data.

\subsection{Visualisasi Partisi}

Setelah dataframe dipartisi, maka tahap selanjutnya adalah memvisualisasikannya ke dalam bentuk scatter plot. Library yang digunakan untuk memvisualisasi partisi dataframe adalah Matplotlib. Hasil visualisasi partisi dataframe dapat dilihat pada Gambar 2. 


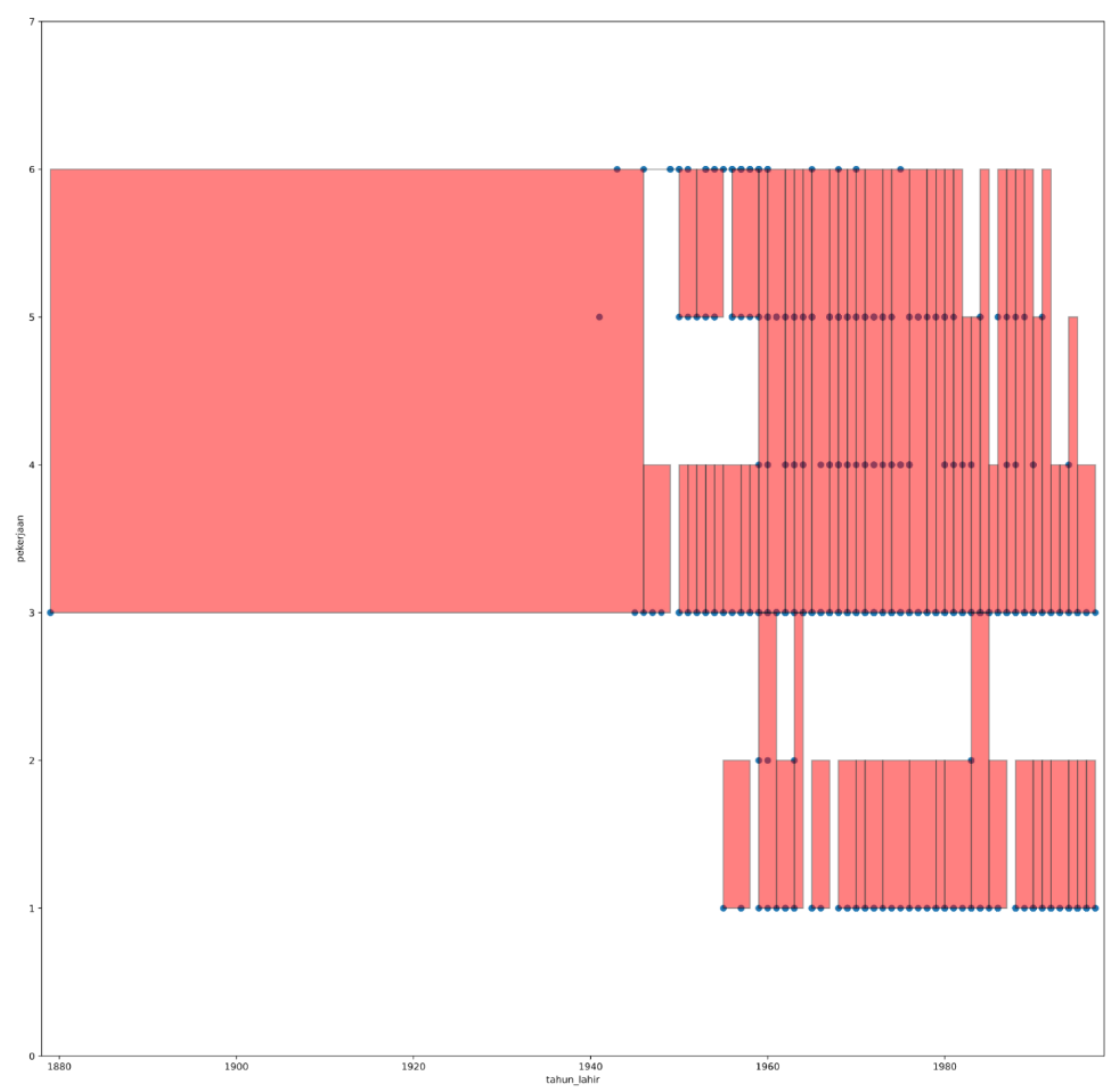

Gambar 2. Hasil visualisasi partisi dataframe.

Dari hasil visualisasi dapat dilihat bahwa kolom pekerjaan berada pada sumbu vertikal dan tahun lahir pada sumbu horizontal. Hasil visualisasi ini menunjukkan bagaimana sebuah data menjadi anonimitas. Semakin samar warna dari scatter plot maka menunjukkan semakin besar anonimitas data tersebut. Dari hasil visualisasi terlihat hampir semua data memiliki anonimitas yang sama. Hal ini dimungkinkan karena jumlah data partisi yang kurang banyak ataupun kurangnya keberagaman data.

\subsection{Menyusun Anonymized Dataset}

Tahapan terkahir adalah menyusun anonymized dataset dan menyimpannya ke dalam format file CSV. Untuk menyusun anonymized dataset dapat menggunakan fungsi dari algoritma Mondrian, yaitu build_anonymized_dataset. Setelah anonymized dataset berhasil tersusun, selanjutnya dapat disimpan dengan menggunakan fungsi $d f$.to_csv yang terdapat pada library Pandas. Sampel hasil anonymized dataset dapat dilihat pada Tabel 7. Hasil anonymized dataset secara lengkap dapat dilihat pada anonymized_dataset.csv [11].

Tabel 7. Sampel hasil anonymized dataset.

\begin{tabular}{cccc}
\hline Tahun Lahir & Pekerjaan & Partai & Count \\
\hline 1956.333 & 1 & PARTAI BULAN BINTANG & 3 \\
\hline 1959.5 & 1.5 & PARTAI AMANAT NASIONAL & 2 \\
\hline 1963 & 1.25 & PARTAI GERAKAN INDONESIA RAYA & 1 \\
\hline 1965.452 & 3.333333 & PARTAI AMANAT NASIONAL & 4 \\
\hline 1969 & 3.48 & PARTAI KEADILAN SEJAHTERA & 3 \\
\hline
\end{tabular}

\section{Kesimpulan}

Penelitian ini mengimplementasikan $K$-Anonymity menggunakan algoritma Mondrian Multidimensional K-Anonymity pada dataset biodata Calon Legislatif untuk Pemilihan Umum Anggota Legislatif di Indonesia pada tahun 2019. Proses diawali dengan inisialisasi dataframe hingga partisi dataset. Setelah didapatkan partisi maka dataset divisualisasikan ke dalam bentuk scatter plot menggunakan Matplotlib. Dari hasil visualisasi terlihat hampir semua data memiliki anonimitas sama, yang dimungkinkan karena jumlah data partisi yang kurang banyak ataupun kurangnya keberagaman data. Oleh karena itu, 
penelitian selanjutnya disarankan untuk menggunakan dataset yang berjumlah banyak dan memiliki banyak keberagaman data. Serta, nilai $k$ pada penggunaan fungsi disesuaikan dengan kebutuhan.

\section{Daftar Pustaka}

[1] GDPR.eu, "What is GDPR, the EU's new data protection law?," 2018. https://gdpr.eu/what-isgdpr/ (accessed Jan. 10, 2021).

[2] P. Regulation, "General Data Protection Regulation," Intouch, 2018.

[3] L. Sweeney, "k-anonymity: A model for protecting privacy," Int. J. Uncertainty, Fuzziness Knowlege-Based Syst., 2002, doi: 10.1142/S0218488502001648.

[4] T. Dalenius, "Finding a needle in a haystack-or identifying anonymous census record," Journal of Official Statistics. 1986.

[5] R. Li et al., "K-anonymity model for privacy-preserving soccer fitness data publishing," 2018, doi: 10.1051/matecconf/201818903007.

[6] L. Meng, X. Hong, Y. Chen, Y. Ding, and C. Zhang, "K-Anonymous Privacy Preserving Scheme Based on Bilinear Pairings over Medical Data," 2020, doi: 10.1007/978-3-030-59016-1_32.

[7] B. B. Mehta and U. P. Rao, "Privacy preserving big data publishing: A scalable k-anonymization approach using MapReduce," IET Softw., 2017, doi: 10.1049/iet-sen.2016.0264.

[8] K. Wang, W. Zhao, J. Cui, Y. Cui, and J. Hu, "A K-anonymous clustering algorithm based on the analytic hierarchy process," J. Vis. Commun. Image Represent., 2019, doi: 10.1016/j.jvcir.2018.12.052.

[9] N. A. Rakhmawati, "The Biodata of Legislative Candidates for Indonesian General Election 2019," Oct. 2019, doi: 10.5281/ZENODO.3474543.

[10] K. LeFevre, D. J. DeWitt, and R. Ramakrishnan, "Mondrian multidimensional K-anonymity," 2006, doi: 10.1109/ICDE.2006.101.

[11] R. P. Pratama, A. Akbar, and N. A. Rakhmawati, "Caleg 2019 Biodata Datasets For K-Anonymity Research,” Jan. 2021, doi: 10.5281/ZENODO.4444802. 